\title{
ANÁLISE DAS ETAPAS DO PROCESSO DECISÓRIO PARA A CONSTRUÇÃO DA POLÍTICA DE ESTÁGIO DA SECRETARIA MUNICIPAL DE SAÚDE DE NATAL/RN
}

\author{
A. S. BARROS*, J. P. MEDEIROS, J. M. M. ARAUJO, F. J. RODRIGUES, R. O. GOMES \\ Instituto Federal do Rio Grande do Norte \\ lesonbarros@gmail.com*
}

Artigo submetido em abril/2014 e aceito em dezembro/2014

DOI: $10.15628 /$ holos.2014.2084

\section{RESUMO}

O presente trabalho visa analisar o processo decisório e suas etapas na elaboração da política de estágio na Secretaria Municipal de Saúde de Natal/RN, observando as bases legais que a fundamentam, as motivações pertinentes a esta idealização e o gerenciamento de conflitos em relação aos grupos de interesse. Com suporte teórico sobre políticas públicas e processo decisório, o trabalho identifica os meios pelos quais a
SMS/Natal norteou suas ações. Para tanto utilizou um questionário com perguntas abertas e consulta a documentos. As informações levantadas apontaram para a prática de um modelo racional de processo decisório, no que diz respeito às suas etapas, com uma agenda aberta e baseada em normativas federais para o estágio na área da saúde.

PALAVRAS-CHAVE: Política de Estágio, Políticas Públicas, Saúde.

\section{ANALYSIS OF THE DECISION MAKING PROCESS STEPS FOR BUILDING POLICY STAGE OF HEALTH'S SECRETARY OF NATAL/RN}

\begin{abstract}
This study aims to analyze the decision-making process and its stages in the preparation training policy in the Municipal Health Secretary of Natal/RN, observing the legal basis for the decision, the relevant motivations to this idealization and conflict management in relation to groups of interest. With theoretical support on public policy and decision-making process, the paper identifies
\end{abstract}

the means by which the SMS/Natal guided their actions. For this we used a questionnaire with open questions and documents. The information gathered pointed to the practice of a rational model of decision making, with an open pointed and based on federal regulations for training in healthcare.

KEYWORDS: Policy of Stage, Public Policies, Health. 


\section{INTRODUÇÃO}

O presente trabalho trata da política de estágio no âmbito da Secretaria de Saúde do Município (SMS) de Natal no Estado do Rio Grande do Norte e tem como enfoque principal a análise do processo decisório e suas etapas para a construção do termo de Convênio e da Normatização da presente política. Este estudo busca, dentre de outras coisas:

- Identificar quais as bases legais (leis, decretos, portarias) que fundamentam a política municipal de estágio.

- Verificar as motivações que levaram à idealização e elaboração da referida política.

- Conceituar e descrever as etapas do processo decisório para formulação da citada política, identificando seus elementos, seu tipo de agenda e, a partir daí, apontar as alternativas encontradas para sanar as dificuldades inicialmente percebidas.

Tendo em vista que o estágio de estudantes, em órgãos públicos ou privados, é algo previsto em lei (Lei Federal no 11.788/2008), torna-se necessário conhecer os seus detalhes, especificando suas exigências e, principalmente, visualizando as oportunidades. Dentro desse contexto o Setor de Desenvolvimento Profissional e Educação na Saúde da SMS/Natal (SDPES/SMS), que faz parte do objeto de estudo dessa pesquisa, foi idealizado há 15 anos tendo como primeiro nome "Setor de Gestão e Educação na Saúde" (SGES), quando, há oito anos, passou a ser denominado com a atual nomenclatura. O referido setor é o responsável por receber, documentar, encaminhar, avaliar e ajudar os estudantes da área da saúde em seu período de prática escolar, ou seja, em seu estágio, seja ele obrigatório ou não. Em decorrência disso, o SDPES/SMS identificou a necessidade de elaborar e regulamentar uma lei municipal específica que os amparasse e lhes assegurasse o respaldo no assunto surgindo, então, depois da aprovação do Conselho Municipal de Saúde de Natal (CMS - Natal/RN), no Fórum de Integração, Educação e Serviços da SMS/Natal (FIESSMS), as Resoluções no 023 e 037, publicadas no Diário Oficial do Município de Natal (DOM), em 06 de novembro de 2012, que são o Termo de Convênio e a Normatização de Estágio, respectivamente. Justifica-se, a partir de então, a importância de tal pesquisa para o âmbito acadêmico, tendo como base uma política de inclusão social e profissional.

Ao explicitar a importância do presente estudo, faz-se necessário apontar, também, a importância do referido estudo para a Secretaria Municipal de Saúde de Natal, e ainda, para a sociedade, pois se trata de uma área social que está inserida na realidade diária de todos, e mais especificamente dos estudantes da área da saúde. Esse estudo se faz importante para a SMS/Natal, pois aponta indicadores que qualificam e quantificam a referida política, no que diz respeito ao seu processo de formulação.

Este trabalho traz, ainda, um referencial teórico sobre as políticas públicas e, mais especificamente, sobre o processo decisório que fundamenta e embasa a pesquisa realizada. Além disso, apresenta-se, na sequência, a metodologia utilizada pelo estudo, com predominância de dados qualitativos coletados através de questionário com questões abertas, além de dados documentais. As considerações finais do trabalho que, de certa forma, esclarecem o motivo pelo qual se fez necessário a elaboração da política, busca responder aos objetivos estabelecidos no início desta introdução. 


\section{REFERENCIAL TEÓRICO}

Essa seção discute a temática 'políticas públicas', tratando de forma mais direta o processo decisório realizado quando da formulação de uma política.

\subsection{Políticas Públicas}

É possível entender uma política pública como todo e qualquer tipo de ação produzida pelo Governo (representante do Estado) (FONSECA, 2013), que visa à melhoria dos serviços oferecidos pelos órgãos públicos, sejam eles federais, estaduais ou municipais. De acordo com Secchi (2010), uma política pública representa uma diretriz para enfrentar um problema público, ou seja, algo que diz respeito à sociedade. Veja sua explicação:

[...] uma política pública é uma orientação à atividade ou à passividade de alguém; as atividades ou passividades decorrentes dessa orientação também fazem parte da política pública; uma política pública possui dois elementos fundamentais: intencionalidade pública e resposta a um problema público; em outras palavras, a razão para o estabelecimento de uma política pública é o tratamento ou a resolução de um problema entendido como coletivamente relevante. (SECCHI, 2010, p. 2)

Segundo Azevedo (2010), apesar dessas políticas terem se evidenciado desde os anos 1930, suas discussões se desencadearam a partir dos anos 1950. As políticas públicas são um novo campo de estudo que se ramificou da ciência política, sendo esta, uma área de estudo voltada especificamente ao âmbito social. No campo das políticas públicas sentiu-se a necessidade de esclarecimentos e aprofundamentos em alguns pontos específicos, por isso que toda política pública precisa explicar a inter-relação entre Estado, Economia, Sociedade e, um último ponto que caminha em todas as esferas citadas anteriormente, a Política. O Governo, que é o produtor da política pública, opta por tomar determinadas decisões e colocar em prática ações que repercutem diretamente na economia e nas sociedades. Dentro desse contexto, Frey (2000) apresenta três dimensões para uma política pública, quais sejam: 1) a dimensão institucional (polity), que investiga o grau de influência de suas estruturas; a dimensão processual (politics), que se refere aos processos de negociação, frequentemente conflituosos; e a dimensão material (policy), que envolve os resultados materiais que se julgam concretos nas decisões políticas, ou seja, sintetizam-se os termos grifados em instituições públicas, processos políticos $e$ conteúdos da política, respectivamente.

Resumindo, "a política pública é um campo de conhecimento que busca, ao mesmo tempo, 'colocar o Governo em ação' e/ou analisar essa ação e, quando necessário, propor mudanças no rumo ou curso dessas ações" (SOUZA, 2006, p. 26). Sabendo-se que é responsabilidade do Governo a provisão de bens e de serviços públicos para a sociedade, as políticas públicas, depois de desenhadas, formuladas e elaboradas, transformam-se e/ou "desdobram-se em planos, programas, projetos, base de dados ou sistemas de informação e de pesquisa". (SOUZA, 2006, p. 26). Ou seja, essas políticas são desenvolvidas através de um ciclo. 


\subsection{Ciclo de políticas públicas}

Uma política pública tem como uma de suas principais características apresentar algum tipo de utilidade para a sociedade, obedecendo a um ciclo de retroalimentação que incluem as etapas da agenda, formulação, execução/implantação e acompanhamento/avaliação (RUA, 2009; SECCHI, 2010; FREY, 2000). Ou seja, a produção das políticas públicas se inicia com a identificação de um ou mais problemas e, a partir disso, a construção de uma agenda é capaz de estimular um debate social/público com a intervenção de autoridades políticas.

A agenda é um conjunto de problemas ou temas entendidos como relevantes. Ela pode tomar forma de um programa de governo, um planejamento orçamentário, um estatuto partidário ou, ainda, de uma simples lista de assuntos que o comitê editorial de um jornal entende como importante. (SECCHI, 2010, p. 36, grifos do autor)

Dessa forma, a agenda, entendida como a forma pela qual são elencados e escolhidos os principais pontos que se pretende mudar/melhorar de uma política pública (FLEXOR; LEITE, 2007), se dá em um processo cognitivo que envolve vários atores em um processo constante de discussão e de definição, como explicitado acima.

Seguindo com as etapas para a produção de uma política pública, têm-se a formulação que é, por sua vez, uma das mais importantes fases de toda a produção, pois é nesse momento que são idealizadas as possíveis soluções dos problemas listados anteriormente (RUA, 2009). A formulação, para acontecer de fato, precisa estar embasada em estudos mais aprofundados (técnicos) e estratégias bem elaboradas, como é visto no trecho a seguir:

A etapa de construção (formulação) de alternativas é o momento em que são elaborados métodos, programas, estratégias ou ações que poderão alcançar os objetivos estabelecidos. Um mesmo objetivo pode ser alcançado de várias formas, por diversos caminhos. (SECCHI, 2010, p. 37, grifo nosso)

Dentro da formulação, há ainda outro fator que é, na realidade, a sequência do estudo técnico, chamado de processo decisório, e que consiste na tomada de decisão, escolhendo a solução mais adequada dentre aquelas idealizadas (FREY, 2000). Porém, tratar-se-á de explicar melhor esse ponto mais adiante no texto. Segue-se a produção da política pública com a execução/implantação que consiste em aplicar um programa de ação (decisão tomada com base na formulação) a um problema. É importante frisar que, dependendo da decisão a ser implementada, o grau de burocracia e o trâmite dos processos podem se tornar maiores, aumentando, na mesma proporção, à distância para o alcance dos objetivos.

Já a implantação, em seu estado simples, trata de realizar, completar uma ação, ou seja, o que existe de visível e palpável, ou quando a política se transforma em programa, após serem aprovadas as diretrizes e legislações que a regulamentam (SOUZA, 2009).

Têm-se ainda, a avaliação ou acompanhamento que, de certa forma, são atividades normativas, tendo em vista a apreciação dos resultados da implementação baseada em quadros demonstrativos que possuem referências, valores e normas. Avaliar consiste em atribuir valor a partir de determinados parâmetros e critérios, relacionando as possibilidades e necessidades de escolha aos objetivos pretendidos, levando em conta que, em muitos casos, devido a problemas externos e mudanças no decorrer do programa, os resultados obtidos nem sempre são os esperados inicialmente (SOUZA, 2009). 
Dessa forma, verifica-se a importância da avaliação e seu papel no ciclo das políticas públicas, a qual permite corrigir os rumos das ações, comparar os objetivos programados e os objetivos alcançados, assim como fornece informações relevantes para a tomada de decisões e o novo planejamento, pois logo se inicia novamente outro ciclo da atividade.

Nesse planejamento, ao se iniciar todo o ciclo, depois das comparações feitas através da avaliação, o processo decisório se torna cada vez mais pertinente, pois ele é formado a partir de fatores estruturais e situacionais, como também, de elementos cognitivos e da personalidade e estratégia dos gestores.

\title{
2.3 Processo Decisório
}

Nas organizações, sejam elas privadas ou públicas, como não poderia ser diferente, os indivíduos tomam decisões, isto é, escolhem entre alternativas em diferentes arenas políticas. Esta tomada de decisão envolve um conjunto de processos políticos que levam à formulação e à implantação das ações práticas e promovem a efetivação da política proposta, não sendo possível definir nele o seu início ou seu final, tendo em vista o emaranhado de decisões tomadas. O processo de tomada de decisão define-se, segundo Robbins (2008), como um processo avaliativo de alternativas que visa à maximização ou a otimização de um estado desejável em reação a um problema existente no estágio atual. Outros autores também expressam sua visão a respeito do assunto, como a seguir:

\begin{abstract}
O processo decisório não é ordenado com princípio, meio e fim definidos, mas com um complexo caminho, que soluções para um grupo podem representar problemas para outro, pois é o resultado de um complexo de decisões tomadas com base em análises técnicas e escolhas racionais individuais e considerações subjetivas. (WENDHAUSEN; CARDOSO, 2007, p. 581)
\end{abstract}

Nessa perspectiva, conforme Dagnino e Gomes (2002), analisar o comportamento de uma instituição de caráter público demanda, em primeira instância, o entendimento de como se dá o processo de tomada de decisão no interior da mesma, pois de acordo com o processo de elaboração de políticas públicas, que costuma ser dividido em três fases sucessivas - Formulação, Implementação e Avaliação -, a política é concebida no âmbito de um processo decisório pelos "tomadores de decisão", que pode ser democrático e participativo ou autoritário e "de gabinete", com ou sem manipulação e controle da agenda dos atores com maior poder. Nesse sentido, quando os autores citam a classificação "democrático e participativo" ou "autoritário e de gabinete" pode-se entender as mesmas como sendo a forma como se dá a tomada de decisão, podendo haver, ou não, participação dos atores a quem interessa a decisão ou, de outra forma, se a decisão será uma imposição dos atores com maior poder [capital social, conforme Wendhausen e Cardoso (2007)].

De forma complementar, o processo decisório também pode ser observado quanto à perspectiva de consenso e conflito e, nesse sentido, seguir a um modelo incremental (LINDBLOM, 1981) ou a um modelo racional (SIMON, 1979).

No modelo incremental, o processo decisório é caracterizado pela negociação e barganha sem a utilização de qualquer procedimento pré-definido ou metodologia específica para guiá-lo. Ele se baseia no simples diálogo entre partidários de interesses e cursos de ação distintos, todos 
eles dispondo, ideal ou teoricamente, de informação plena e poder indiferenciado. O resultado do processo é um ajuste entre eles, uma solução de compromisso entre os seus interesses, uma "média" entre as proposições de cada um (ROBBINS, 2008).

Segundo Dagnino e Gomes (2002), este modelo apresenta caráter frequentemente precário, sendo passível a utilização de mecanismos de controle da agenda de decisão; a omissão de conflitos; a manipulação de interesses e a contratação da agenda aos assuntos "seguros" levando à situação de não tomada de decisão, favorecendo as elites de poder. Conforme Wendhausen e Cardoso (2007), esse caráter expressa-se através de vários fatores, como: o fato de determinadas reivindicações não aparecerem na agenda; facilidade de acessos aos "tomadores de decisão" por alguns participantes e outros não; possibilidade de alguma liderança levar o problema às autoridades; alguns membros da burocracia desempenharem função importante na indicação de problemas às autoridades e a aceitabilidade de determinados assuntos pelos especialistas. Nesse sentido, uma das tendências da adoção desse modelo é apresentá-lo como resultado de um "consenso", pois muitas vezes passa-se por critérios que favorecem as elites do poder, geralmente obtido através de barganha e que possui um caráter passageiro na medida que se pode desfazer quando da implementação da política.

O segundo modelo que pode ser adotado no processo de formulação da política, de acordo com Dagnino e Gomes (2002), é o modelo racional. Tal modelo envolve a utilização do planejamento e das metodologias normalmente a ele associadas, como apoio ao processo decisório. Conforme Simon (1979), a pessoa que toma decisões é racional, ou seja, faz escolhas consistentes, maximizando o valor dentro de certos limites. Essas escolhas seguem seis passos: 1 ) definir o problema, 2) identificar os critérios para a decisão, 3) pesar os critérios, 4) desenvolver alternativas, 5) avaliar as alternativas e 6) escolher a melhor alternativa. A adoção à risca deste modelo envolve uma minuciosa definição dos interesses, valores e objetivos de cada um dos atores partidários, e cursos de ação distintos, diferenciando-se do modelo incremental, pois se levado a efeito de modo cabal, obriga à explicitação de conflitos encobertos e latentes existindo nesse caso um elemento concreto - o plano - que explicita o acordo alcançado contemplando a avaliação do cumprimento das metas, prazos etc. Observa-se que o fato do processo decisório ou momento da formulação seguir um dos modelos, faz a definição da agenda ser um dos elementos de notória atenção nesse momento.

Assim, para Pinto (2008), a inclusão/exclusão de determinado assunto na agenda vai depender de dois fatores: dos participantes ativos (governamentais e não governamentais) e dos processos pelos quais os itens da agenda ganham proeminência, o que pode acontecer através de grupos de interesses que procuram fazer valer seus interesses junto ao poder público.

Porquanto, no processo de decisão, para incluir ou excluir os assuntos, ocorre uma desigualdade entre os formuladores e os cidadãos. Esta desigualdade é visível na capacidade de conhecimento ou de informação do assunto tratado, onde os cidadãos nem sempre têm o conhecimento dos assuntos públicos, capacidade de análise, ou êxito nas relações interpessoais, o que os atrapalha na participação. Porém, faz-se necessário, mesmo assim, essa abertura aos cidadãos, como lê-se a seguir:

Em consequência, para que exista uma forma de governo democrático é necessária à máxima participação da sociedade, pois ela tem um efeito integrativo e ajuda o individuo a aceitar as decisões coletivas que promove e 
desenvolve as próprias qualidades que lhes são necessárias, ou seja, quanto mais os indivíduos participam, melhor capacitados eles se tornam para fazê-lo. (WENDHAUSEN; CARDOSO, 2007, p.581)

Por fim, para que haja essa participação, faz-se necessário existir interesse por parte da população, assim como conhecimento acerca dos assuntos explorados para que a participação se torne efetiva. No caso em estudo, o interesse se deu embrionariamente pela Secretaria de Saúde de Natal que, após alguns estudos, decidiu abrir o assunto também a todos que se interessassem pela pauta, como explicado à frente.

\section{MÉTODO}

A pesquisa deve ter um caráter pragmático, o que, segundo Gil (2002), consiste em um processo racional e sistemático de desenvolvimento do método científico com o objetivo fundamental de descobrir respostas para problemas mediante o emprego de procedimentos científicos. Para tanto, este trabalho tem caráter exploratório e descritivo e foi realizado dentro de uma abordagem qualitativa. De acordo com Severino (2007), uma pesquisa exploratória tem em vista o levantamento de informações acerca de determinado problema, indicando uma área de trabalho, mapeando as condições de manifestação do problema. Ainda nessa classificação, Severino (2007) aborda a pesquisa descritiva como sendo aquela que observa, registra e analisa as características dos fatos ou fenômenos estudados. Quanto a perspectiva qualitativa, Marconi e Lakatos (2004) afirmam:

[...] é por meio do método qualitativo, que o investigador entra em contato direto e prolongado com o indivíduo ou grupos humanos, com o ambiente e a situação que está sendo investigada, permitindo um contato de perto com os informantes. (p. 271)

A coleta de dados aqui realizada se deu de duas formas: através de pesquisa documental, com consultas a leis, decretos e normatizações, e mediante questionário estruturado. Para tanto foi feito uso de cinco categorias de análise: 1) as bases legais para a elaboração da política de estágio em saúde na SMS/Natal; 2) as motivações para elaboração da política de estágio na SMS/Natal; 3) as etapas do processo decisório na política de estágio na SMS/Natal; 4) o tipo de agenda presente na formulação da política de estágio na SMS/Natal; 5) as alternativas encontradas para sanar as principais dificuldades na política em estudo.

Torna-se importante ressaltar que essa pesquisa se tornou possível a partir da abordagem a uma pessoa participante do Fórum de Integração, Ensino e Serviços da Secretaria Municipal de Saúde (FIESSMS) e que, no momento da coleta dos dados, ocupava um cargo de coordenação na SMS de Natal.

Assim, foram dois os instrumentos de pesquisa utilizados. Foi feita análise documental do Termo de Convênio de Estágio e da Normatização do Estágio (NATAL, 2012a; NATAL, 2012b), ambos publicados no Diário Oficial do Município de Natal de 06 de Novembro de 2012, assim como, a Lei Federal de Estágio (BRASIL, 2008), publicada no Diário Oficial da União de 26 de setembro de 2008. Também foi utilizado um questionário com perguntas abertas, que foi respondido sujeito da pesquisa citado anteriormente. Esse questionário foi elaborado a partir das contribuições de Simon (1979), no que diz respeito às etapas do processo decisório. Dessa forma, 
- levantamento dos dados aconteceu em dois momentos: no primeiro momento houve a identificação das bases legais (leis, decretos e normatizações) e no segundo, a aplicação do questionário.

Em um único momento com a pessoa participante do estudo não foi possível esclarecer todos os detalhes exigidos pela pesquisa, sendo necessários contatos por e-mail e telefone, o que garantiu maior propriedade acerca do assunto. Depois de sanadas as dúvidas existentes quanto às respostas dadas, o texto produzido foi encaminhado ao respondente para apreciação, aceitação e modificação (se necessário) e, logo após, procedeu-se com a finalização do presente texto.

\section{ANÁLISE DO PROCESSO DECISÓRIO NA POLÍTICA DE ESTÁGIO NA SMS/NATAL}

A Política de Estágio da Secretaria Municipal de Saúde de Natal/RN tem suas bases legais em documentos federais e em leis específicas do Ministério da Saúde. Dentro desse contexto, pode-se apontar primeiramente a Constituição da República Federativa do Brasil que, em seu artigo 196, diz que "a saúde é direito de todos e dever do estado garantido mediante políticas sociais e econômicas que visem [...] ao acesso universal e igualitário às ações e serviços para sua promoção, proteção e recuperação" (BRASIL, 2010, p. 131). No que diz respeito à oferta de serviços de saúde, nota-se que, a Constituição Federal também trata da participação de instituições privadas na assistência à saúde, pois, de acordo com seu artigo 199, § 10: "As instituições privadas poderão participar de forma complementar ao Sistema Único de Saúde SUS, segundo diretrizes deste, mediante contrato de direito público ou convênio, tendo preferência às entidades filantrópicas e as sem fins lucrativos" (BRASIL, 2010, p. 132).

Ainda na Constituição Federal, observa-se que a Política em questão utiliza-se do artigo 200, inciso III, que trata das atribuições do SUS: “Ao Sistema Único de Saúde compete, além de outras atribuições, nos termos da lei: ordenar a formação de recursos humanos na área da saúde" (BRASIL, 2010, p. 132). A partir destes artigos da Constituição Federal (art. 196, art. 199, § 1ㅇ e art. 200, III), o Ministério da Saúde regulamentou através das Leis no 8.080 (BRASIL, 1990a), de 19 de setembro de 1990, e 8.142 (BRASIL, 1990b), de 28 de dezembro de 1990, ambos publicados no Diário Oficial da União nas datas de 20 de setembro de 1990 e 31 de dezembro de 1990, respectivamente, o Sistema Único de Saúde - SUS, que dispõe sobre as condições de promoção da saúde. De acordo com a Lei no 8.080, em seu artigo 60 e inciso III, percebe-se que está intrínseco ao Sistema Único de Saúde - SUS, a ordenação da formação de recursos humanos na área da saúde. Assim sendo, e em comunhão com o artigo 14임 da mesma Lei, deverão ser criadas comissões permanentes de integração entre os serviços de saúde e as instituições de ensino profissional e superior (BRASIL, 1990). Em complemento a esta diretriz, nota-se em seu parágrafo único:

Cada uma dessas comissões terá por finalidade propor prioridades, métodos e estratégias para a formação e educação continuada dos recursos humanos do Sistema Único de Saúde-SUS, na esfera correspondente, assim como em relação à pesquisa e à cooperação técnica entre essas instituições. (BRASIL, 1990, p. 18056) 
Tendo como bases principais estes artigos - associados ao artigo 15으, inciso IX da Lei 8.080/1990, onde se lê "A União, os estados, o Distrito Federal e os municípios exercerão, em seu âmbito administrativo, as seguintes atribuições: [...] participação na formulação e na execução da política de formação e desenvolvimento de recursos humanos para a saúde [...]" (BRASIL, 1990, p. 18057), os profissionais do setor de estágio na saúde, no âmbito municipal de Natal/RN, sentiram a necessidade de instituir e normatizar o acesso dos estudantes às unidades de saúde locais, tendo em vista a não organização e o não preparo para receber os mesmos, sendo, o resultado dessa necessidade, a Proposta de Convênio entre as Instituições de Ensino Públicas, Privadas, Filantrópicas e Escolas Técnicas em Saúde (NATAL, 2012a) e a Normatização de Estágio (NATAL, 2012b), publicadas no Diário Oficial do Município de 06 de novembro de 2012, que são o complemento de que trata o Decreto Municipal no 8.650, de 29 de Janeiro de 2009, em seu artigo no 15, que diz: "A Secretaria Municipal de Administração, Recursos Humanos e Previdência baixará as normas complementares a este Decreto" (NATAL, 2009, p. 2).

No âmbito da SMS/Natal foi idealizado, primeiramente, a elaboração de um conjunto de normas que pudesse preencher lacunas existentes no Setor de Desenvolvimento Profissional e Educação na Saúde (SDPES). Esse setor tem como principais atribuições:

- Fazer o levantamento das unidades que recebem estagiários e mantê-lo atualizado.

- Comunicar ao Fórum das Escolas o novo termo de convênio e suas mudanças (se houverem).

- Fazer memorando circular para os distritos sanitários, informando as mudanças na nova normatização, como também, explicando o novo caminho para a entrada dos alunos na rede.

- Reunir-se com os representantes dos setores de Gestão de Pessoas dos distritos sanitários, para a apresentação dos termos de convênio, assim como, para sanar possíveis dúvidas que venham a existir.

- Verificar, junto às unidades de saúde, o número de vagas disponíveis por campo de atuação.

- Cadastrar os preceptores dos estudantes.

- Enviar, às unidades de ensino, a documentação necessária para a renovação do convênio com a SMS.

- Fazer edital para publicação no Diário Oficial do Município, informando às Instituições de Ensino e os campos de estágio que estão disponíveis.

- Realizar encontros com o Fórum de Integração, Ensino e Serviços da SMS/Natal (FIESSMS), para discutir os cenários de práticas dos estágios e prestar esclarecimentos sobre a documentação para a SMS autorizar as práticas na rede.

- Registrar modelos para o estágio obrigatório do tipo: termo de anuência, carta de concessão, coleta de dados etc.

- Alimentar a planilha do setor (SDPES) com os dados dos estagiários, inclusive seus e-mails.

- Receber os estagiários na secretaria e prestar orientações do tipo: respeito, desempenho, vestimentas, posturas, hierarquização, assiduidade, pontualidade e discrição, ou seja, as informações necessárias para o início da prática. 
- Elaborar e encaminhar minutas de oficio para renovação de contrato, substituição de estagiário, cancelamento de estágio e pedidos de vale transporte para cada contrato assinado junto à SMS/Natal.

Através do questionário enviado e de contatos confirmatórios com o sujeito da pesquisa, foi possível entender que um dos principais motivos que incentivou a elaboração da normatização e do termo de convênio em questão, foi a liberalidade com relação à demanda de estagiários, emitida pelas instituições de ensino. Essa demanda era significativa e fazia com que não se identificasse, ao certo, o número de estagiários distribuídos nas unidades municipais, bem como, não se tinham documentos que assegurassem os respectivos estagiários quanto aos acidentes laborais, deslocamento, bolsa remuneração e outros itens. Faz-se necessário expressar que os motivos listados acima foram identificados no dia-a-dia pelos próprios profissionais da área do estágio, através da realidade vivida tanto por estes, como pelos estagiários. No mesmo sentido, existia também, a necessidade de fundamentação com relação à normatização idealizada. A partir de estudos e pesquisas realizadas na área, o documento que - após a Constituição Federal Brasileira de 1988, as Leis 8.080/1990 e 8.142/1990 do Ministério da Saúde, citados anteriormente -, serviu de base técnica para a elaboração específica de normatização de estágio no âmbito municipal, foi a Lei Federal no 11.788, de 25 de setembro de 2008, publicada no Diário Oficial da União em 26 de setembro de 2008, que dispõe sobre o estágio de estudantes, e foi elaborada e expedida pelo Ministério do Trabalho e Emprego.

Em posse destes documentos, foi criado junto ao Conselho Municipal de Saúde de Natal o Fórum de Integração, Ensino e Serviços da Secretaria Municipal de Saúde (FIESSMS), que era formado pelos Coordenadores de Estágio e Educação Permanente da SMS/Natal (SDPES), Diretores dos Cursos da área da Saúde das Instituições de Ensino Superior e de Escolas Técnicas do município de Natal, e pelos representantes do Conselho Municipal de Saúde de Natal, e tinha como objetivo principal elaborar a Normatização e o Termo de Convênio, hoje vigentes, e isso se tornou possível através de reuniões para exposição de problemas e dificuldades por parte dos interessados na política de estágio no âmbito municipal de Natal.

Como visto no suporte teórico, apresentado anteriormente, em uma política pública existe um ciclo que se reinicia a cada fase terminada, quais sejam as fases do ciclo: agenda, formulação, implantação e execução/avaliação, sendo este o seu final e reinício, pois a avaliação é o momento de analisar se os objetivos vislumbrados no início do processo foram realmente alcançados. Porém, uma das fases mais importante do processo é justamente a agenda, que é onde tudo se principia. Dependendo dos participantes que fazem a agenda, esta pode ser elaborada visando às necessidades técnicas ou não, podendo variar também os impactos causados por essa política na sociedade. Existem, portanto, as agendas abertas e restritas, de forma que a 'aberta' inclui os interessados na implementação e execução das políticas - ou seja, no caso da política em análise os interessados são, dentre outros, os estagiários e seus representantes -, e a 'restrita', como o próprio nome já sintetiza, é limitada à parte gestora estratégica de elaboração da mesma.

Assim o processo decisório relativo à elaboração da política municipal de estágio pode ser considerado como envolvido por uma agenda aberta, tendo em vista a participação nos Fóruns dos representantes dos cursos ligados à saúde, que são externos à SMS/Natal. As reuniões contavam com vários diretores e representantes das escolas de ensino técnico e superior ligadas à saúde. Com o decorrer do tempo o processo de formulação de agenda, para o diagnóstico 
inicial, formulação e implementação da política, que durou, em média, seis anos, passou a ser esvaziado, de forma que, os últimos remanescentes foram os diretores de cursos da Escola de Enfermagem de Natal, ligada à Universidade Federal do Rio Grande do Norte (ensino técnico e superior), os diretores dos cursos da saúde da atual UNI-RN (ensino superior) e os representantes da Escola de Enfermagem Menino Jesus (ensino técnico) o que, de certa forma, os deixou com minoria na votação das propostas elencadas pelos gestores públicos.

No que diz respeito à busca pelo consenso e/ou resolução de conflitos com os representantes das instituições participantes do Fórum (FIESSMS), que se reunia, no período da coleta dos dados, uma vez por mês, o sujeito da pesquisa afirmou ter enfrentado várias dificuldades como, a falta de assiduidade dos participantes nos encontros e a demora na votação e elaboração das normas. O aspecto que mais teria dificultado e atrasado todo o processo, contudo, foi associado à dificuldade de aceitabilidade nas contrapartidas por parte das convenentes (Instituições de Ensino Superior e Técnico ligadas a área da saúde que firmaram o Termo de Convênio de Estágio), mais precisamente nos itens II, III, IV e V, da cláusula 11a (Décima Primeira) do Termo de Convênio de estágio (NATAL, 2012a) que se referem às instituições de ensino privadas, filantrópicas, organizações sociais, universidades, centros universitários, faculdades e escolas técnicas. Nessa cláusula, as instituições de ensino repassariam à SMS/Natal, em forma de doação, materiais de insumo e consumo para a administração pública. As instituições não concordaram inicialmente e relutaram até certo ponto, quando resolveram ceder às propostas sugeridas. Coloca-se, neste momento, como explicação às dificuldades apresentadas pelas escolas e instituições privadas, toda uma readequação que estas escolas sofreriam para atender aos quesitos selecionados, tendo em vista a liberalidade anterior às resoluções. Resgatando resumidamente algumas das ideias apresentadas anteriormente no referencial teórico, o que foi solução para uma das partes (a SMS/Natal), a partir de uma visão e de um estudo técnico, tornou-se problema para a outra (as Instituições de Ensino Privadas).

Diante de todo o processo a que se submeteu a aceitação da referida política, e em resposta às questões elaboradas pelos pesquisadores, pode-se afirmar que as alternativas encontradas para sanar os problemas expressados pelos profissionais do setor de estágio da SMS/Natal estão embasadas perante a Constituição Federal de 1988, nos artigos 196, 199, § 10 e 200으, inciso III (BRASIL, 2010), perante a Lei no 11.788/2008 (BRASIL, 2008), como também, das Leis do Ministério da Saúde, Leis no 8.080/1990 e no 8.142/1990 (BRASIL, 1990a; BRASIL, 1990b) e foram aprovadas pelo Conselho Municipal de Saúde de Natal (CMS/Natal-RN) nos encontros do Fórum (FIESSMS), sendo elas, as Resoluções Municipais no 023 (NATAL, 2012a) e no 037 (NATAL, 2012b), publicadas em Diário Oficial do Município (DOM), na data de 06 de novembro de 2012, conforme explicitado anteriormente.

\section{CONSIDERAÇÕES FINAIS}

Tomando como base principal os objetivos específicos, listados e expressos anteriormente, assim como, o questionário elaborado e encaminhado ao sujeito da pesquisa, fazse necessário explicitar e compilar toda a análise apresentada. Primeiramente e notadamente, foram identificadas e mostradas várias bases legais que serviram de caminho norteador para e elaboração da normatização municipal de estágio na área de saúde. A Constituição Federal do Brasil de 1988 (artigos 196, 199, § 1ํ e 200, III), as Leis do Ministério da Saúde que regulamentam 
o Sistema Único de Saúde - SUS (Leis 8.080/1990 e 8.142/1990), a Lei Federal do Ministério do Trabalho e Emprego que trata do estágio de estudantes (Lei no 11.788/2008), assim como, o Decreto Municipal no 8.650/2009 que regulamenta o estágio de estudantes em órgãos municipais de Natal.

No que diz respeito à identificação das motivações principais à criação dessa normatização municipal destaca-se a necessidade de oficializar as práticas de aprendizagem e a falta de documentos que assegurassem, tanto estudantes como preceptores, o controle da alta demanda de estagiários emitida pelas instituições que atuavam na área de saúde.

Para a elaboração e consolidação dessas políticas (Normatização de Estágio e do Termo de Convênio) foram identificadas as seguintes etapas do processo decisório: idealização, elaboração e formulação da política (através dos documentos citados acima que a fundamentam); implantação desta, através das publicações em Diário Oficial do Município e efetivação da política por meio do acompanhamento das diretrizes oficializadas que, de certa forma, foram às alternativas encontradas para sanar as dificuldades apresentadas no início do processo. Estas dificuldades tratavam de: obediência ao número máximo de estagiários por setor/unidade de saúde, documentos como "Termo de Compromisso de Estágio e Seguro de Vida" que oficializam e asseguram os envolvidos na prática escolar e, por fim, contrapartidas por parte das instituições de ensino, tanto de materiais de insumo e consumo como espaços físicos e profissionais para cursos e capacitações.

De forma a atender um terceiro objetivo do trabalho, considera-se que a política municipal de estágio pode ser caracterizada como "democrática e participativa" e de agenda aberta, tendo em vista a participação, inclusive na votação das propostas, dos atores interessados na política, quais sejam os diretores de cursos das instituições de ensino ligadas à área da saúde, além de representantes dos estagiários, em um modelo de tomada de decisão do tipo "racional", no qual as decisões são tomadas com base em escolhas consistentes que obedecem a certos limites concretizados através de seis passos: 1) A definição do problema, no caso estudado compreende-se como a não oficialização/regulamentação de uma política municipal de estágio na saúde, tendo, em decorrência disso, uma enorme liberalidade quanto ao encaminhamento dos estudantes por parte das instituições de ensino; 2) a identificação dos critérios para decisão: envolveu a necessidade de criação e normatização da política, as exigências para o estágio, a necessidade de fundamentação teórica que sustente a política municipal, a necessidade de oferecer oportunidades de estágio para a prática escolar visando à promoção e capacitação profissional, entre outras; 3 ) pesar os critérios: consistiu em avaliar e priorizar os critérios de maior necessidade de resolução, por exemplo, a criação de uma normatização que esteja fundamentada em um documento maior (Constituição Federal), a necessidade de oferecer estágio e assim por diante; 4) desenvolver alternativas: versava sobre a criação de consórcios e/ou convênios nos quais existam partidas e contrapartidas, ações e compensações; 5) avaliar as alternativas: compreendeu a verificação, dentre as alternativas listadas, de quais seriam as mais viáveis para o bom funcionamento do serviço público de modo geral e; por fim, 6) escolher a melhor alternativa: consistiu em fazer a melhor escolha, com base nas avaliações do item anterior, onde as compensações e contrapartidas fossem mais favoráveis.

Diante do exposto, relatam-se algumas limitações inerentes ao presente trabalho: 1) pouco tempo disponível, por parte do sujeito da pesquisa, o que fez com que em um primeiro momento não fosse possível levantar todas as informações relevantes para o estudo, sendo 
necessários contatos posteriores por e-mail e telefone; 2) a opção pelo envio do texto produzido a partir das respostas dadas pelo sujeito para o mesmo apreciá-lo e/ou modificá-lo (se necessário), pode ser considerado como um fator limitador do estudo; 3) a adoção de um método relativamente simples, tendo em vista se tratar de um estudo empírico; e 4) o recorte temporal da pesquisa que atribui ao estudo características específicas apenas do momento no qual foi realizada a pesquisa.

A partir destas limitações aqui apresentadas, sugere-se a realização de estudos futuros que priorizem uma análise longitudinal da situação-problema, que se utilize de análises mais complexas, e que possa abordar diferentes atores envolvidos no processo.

Por fim, e atendidas às expectativas dos autores de responder aos pontos listados no início do estudo, o trabalho é finalizado com o intuito de enriquecer o conhecimento dos leitores que porventura se interessem pela matéria ou que, da mesma forma, pesquisem sobre o tema.

\section{REFERÊNCIAS}

1. AZEVEDO, Márcio Adriano de. Avaliação do programa escola ativa como política pública para as escolas rurais com turmas multisseriadas: a experiência em Jardim do Seridó/RN (1998-2009). 2010, 213f. Tese (Doutorado em Educação) - Universidade Federal do Rio Grande do Norte, Natal, 2010.

2. BRASIL. CONSTITUIÇÃO (2010). Constituição da República Federativa do Brasil: promulgada em 5 de outubro de 1988. Brasília: Secretaria Especial de Editorações e Publicações, 2010.

3. BRASIL. Lei $n$ ㅇ 8.080, de 19 de setembro de 1990. Dispõe sobre as condições para a promoção, proteção e recuperação da saúde, a organização e o funcionamento dos serviços correspondentes e dá outras providências. Diário Oficial da União [da] República Federativa do Brasil, Brasília, 20 set. 1990a.

4. BRASIL. Lei no 8.142, de 28 de dezembro de 1990. Dispõe sobre a participação da comunidade na gestão do Sistema Único de Saúde (SUS) e sobre as transferências intergovernamentais de recursos financeiros na área da saúde e dá outras providências. Diário Oficial da União [da] República Federativa do Brasil, Brasília, 31 dez. 1990b.

5. BRASIL. Lei no 11.788 , de 25 de setembro de 2008. Dispõe sobre o estágio de estudantes. Diário Oficial [da] República Federativa do Brasil, Brasília, 26 set. 2008.

6. DAGNINO, R.; GOMES, Erasmo J. O Processo Decisório na Universidade Pública Brasileira: uma visão de Análise de Política. Revista Avaliação, Campinas, v. 7, n. 4, p. 43-72, 2002.

7. FLEXOR, G.; LEITE, S. P. Análise das políticas públicas: breves considerações teóricometodológicas. In: ENCONTRO NACIONAL DE ECONOMIA POLÍTICA, 12., 2007, São Paulo. Anais... São Paulo: SEP, 2007.

8. FONSECA, Francisco. Dimensões críticas das políticas públicas. Cadernos EBAPE.BR, Rio de Janeiro, v. 11, n. 3, set./nov. 2013.

9. FREY, Klaus. Políticas Públicas: um debate conceitual e reflexões referentes à prática da análise de políticas públicas no Brasil. Planejamento e Políticas Públicas. Brasília, IPEA, n. 21, jun. 2000. 
10. GIL, Antônio Carlos. Como elaborar projetos de pesquisa. São Paulo: Atlas, 2002.

11. LINDBLOM, C. E. O processo de decisão política. Brasília: Editora UnB; 1981.

12. MARCONI, Marina de Andrade; LAKATOS, Eva Maria. Metodologia científica. São Paulo: Atlas, 2004.

13. NATAL. Decreto no 8.650, de 29 de janeiro de 2009. Regulamenta o estágio de estudantes em órgãos municipais. Diário Oficial [do] Município de Natal, Natal, 30 jan. 2009.

14. NATAL. Resolução no 023/2012, de 06 de novembro de 2012. Proposta de Convênio entre as Instituições de Ensino Públicas, Privadas, Filantrópicas e Escolas Técnicas em Saúde e a Secretaria Municipal de Saúde de Natal/RN (SMS/Natal/RN), para realização de Estágio Obrigatório e Estágio Não Obrigatório. Diário Oficial [do] Município de Natal, Natal, n. 2391, p. 3-6, 6 nov. 2012 a.

15. NATAL. Resolução no 037/2012, de 06 de novembro de 2012. Proposta de normatização de estágios na SMS/Natal/RN. Diário Oficial [do] Município de Natal, Natal, n. 2391, p. 6-8, 6 nov. 2012b.

16. PINTO, Isabela Cardoso M. Construção da agenda governamental: atores, arenas e processo decisório na saúde. Organização e Sociedade, v.15, n. 44, p. 13-23, jan./mar. 2008.

17. ROBBINS, Stephen P. Comportamento organizacional. São Paulo: Pearson Prentice Hall, 2005.

18. RUA, Maria das Graças. Políticas públicas. Florianópolis: UFSC/CAPES/UAB, 2009.

19. SECCHI, Leonardo. Políticas públicas: conceitos, esquemas de análises, casos práticos. São Paulo: Cengage Learning, 2010.

20. SEVERINO, Antonio Joaquim. Metodologia do trabalho científico. São Paulo: Cortez, 2007.

21. SIMON, Herbert. A. Comportamento administrativo: estudo dos processos decisórios nas organizações administrativas. Rio de Janeiro: Fundação Getúlio Vargas, 1979.

22. SOUZA, Celina. Políticas Públicas: uma revisão da literatura. Sociologias. Porto Alegre, v. 8, n. 16, p. 20-45, jul./dez. 2006.

23. SOUZA, Lincoln Moraes de. Políticas Públicas: introdução às atividades e análise. Natal: EDUFRN, 2009.

24. WENDHAUSEN, Águeda; CARDOSO, Sandra de Mello. Processo decisório e Conselhos Gestores de Saúde: aproximações teóricas. Revista Brasileira de Enfermagem. Brasília, v. 60, n. 5, p. 579-84, set./out. 2007. 